OPEN ACCESS

Edited by:

Gilles Colinet,

University of Liège, Belgium

Reviewed by:

Sudipta Rakshit,

Tennessee State University,

United States

Markus Puschenreiter,

University of Natural Resources and

Life Sciences Vienna, Austria

*Correspondence:

Carlos Garbisu

cgarbisu@neiker.eus

Specialty section:

This article was submitted to Soil Processes,

a section of the journal

Frontiers in Environmental Science

Received: 01 July 2021

Accepted: 30 August 2021

Published: 16 September 2021

Citation:

Alkorta I and Garbisu C (2021)

Reflections and Insights on the Evolution of the Biological Remediation

of Contaminated Soils.

Front. Environ. Sci. 9:734628.

doi: 10.3389/fenvs.2021.734628

\section{Reflections and Insights on the Evolution of the Biological Remediation of Contaminated Soils}

\author{
Itziar Alkorta ${ }^{1}$ and Carlos Garbisu ${ }^{2 *}$ \\ ${ }^{1}$ Department of Biochemistry and Molecular Biology, University of the Basque Country, UPV/EHU, Bilbao, Spain, ${ }^{2}$ NEIKER- \\ Basque Institute of Agricultural Research and Development, Basque Research and Technology Alliance (BRTA), Parque Cientifico \\ y Tecnológico de Bizkaia, Derio, Spain
}

The field of soil biological remediation was initially focused on the use of microorganisms. For organic contaminants, biostimulation and bioaugmentation were the strategies of choice. For heavy metals, bioremediation was centered on the feasibility of using microorganisms to reduce metal toxicity. Partly due to the impossibility to degrade metals, phytoremediation emerged proposing the use of plants to extract them (phytoextraction) or reduce their bioavailability (phytostabilization). Later, microbialassisted phytoremediation addressed the inoculation of plant growth-promoting microorganisms to improve phytoremediation efficiency. Similarly, plant-assisted bioremediation examined the stimulatory effect of plant growth on the microbial degradation of soil contaminants. The combination of plants and microorganisms is nowadays often recommended for mixed contaminated soils. Finally, phytomanagement emerged as a phytotechnology focused on the use of plants and associated microorganisms to decrease contaminant linkages, maximize ecosystem services, and provide economic revenues. Although biological remediation methods have been in use for decades, the truth is that they have not yet yielded the expected results. Here, we claim that much more research is needed to make the most of the many ways that microorganisms have evolutionary developed to access the contaminants and to better understand the soil microbial networks responsible, to a great extent, for soil functioning.

Keywords: bioremediation, phytoremediation, symbiosis, bioavailability, microbial adaptations, soil microbial networks

\section{INTRODUCTION}

Soil contamination is an environmental problem that entails a serious threat to human and ecosystem health. After decades of research and development on soil remediation, the frustrating reality is that we still cannot effectively (in terms of both contaminant removal and soil health recovery) and economically remediate many, if not most, contaminated soils. As a consequence, many contaminated soils are still simply excavated and then transported to a licensed landfill (the so-called "dig and dump" method). Traditional physicochemical methods of soil remediation are often economically-unfeasible and usually have an adverse impact on the integrity of the soil ecosystem (Ali et al., 2013). Biological methods are generally less disruptive but, instead, they are frequently less efficient and effective in terms of contaminant removal, as well as 
much less reproducible (they are typically too case-specific) (Lacalle et al., 2020). To complicate matters further, many contaminated soils are characterized by the simultaneous presence of organic and inorganic contaminants (the so-called mixed contaminated soils), making their remediation more difficult than it is already (Lacalle et al., 2018).

In the last years and decades, it has been widely emphasized that the ultimate goal of soil remediation methods must be not only to decrease the total and/or bioavailable concentration of the contaminants but to restore soil health (Epelde et al., 2014), i.e., "The ability of the soil to sustain the productivity, diversity, and environmental services of terrestrial ecosystems" (FAO, 2020). The crucial concept behind this statement is that, as it is often the case with many physicochemical methods, it is not acceptable to reduce the concentration of soil contaminants at the expense of negatively affecting, sometimes irreversibly, the integrity of the soil ecosystem (Gómez-Sagasti et al., 2016). For this reason, as well as for their being more cost-effective and less labor-intensive, biological methods of soil remediation are commonly recommended despite their well-known limitations: cleanup and remediation take more time (compared to physicochemical methods of soil remediation); lack of reproducibility; and other limitations derived from contaminant distribution, soil nutritional status, humidity, $\mathrm{pH}$, temperature, presence of electron acceptors, etc. (Hussain et al., 2018).

\section{BIOREMEDIATION}

Initially, the field of soil biological remediation was focused on the use of microorganisms (mainly, bacteria and fungi) to clean up soils contaminated with organic contaminants, particularly, petroleum hydrocarbons (Wartell et al., 2021). Together with natural attenuation (i.e., bioremediation naturally performed by the native microorganisms), biostimulation and bioaugmentation have traditionally been the strategies of choice for the bioremediation of soils contaminated with petroleum hydrocarbons, mineral oils, polycyclic aromatic hydrocarbons, polychlorinated biphenyls, and pesticides (Megharaj et al., 2011).

Biostimulation deals with the modification of the environmental conditions (e.g., soil nutrients, moisture, $\mathrm{pH}$, oxygen, temperature) to stimulate contaminant biodegradation (Wu et al., 2019). Biostimulation treatments often fail when contaminants are persistent or recalcitrant (e.g., POPs or persistent organic pollutants), but they have shown their effectiveness for easily degradable organic contaminants. However, in many cases, after an initial phase of rapid contaminant degradation, the rate of contaminant removal decreases until reaching a plateau (Barrutia et al., 2011), which frequently corresponds to a contaminant concentration still above the regulatory limit.

Bioaugmentation is based on the inoculation of degrading microbial strains which have been selected under laboratory conditions because of their capacity to rapidly degrade the target contaminants. The degrading strains can be inoculated singly or in combination as microbial consortia (Poi et al., 2017;
Hassan et al., 2020). In some cases, fungi (mycoremediation) and bacteria are simultaneously inoculated (Zaborowska et al., 2019) with potential synergistic effects. Both strategies (biostimulation and bioaugmentation) have been largely used with varying degrees of success but, in particular, the use of bioaugmentation has produced many more failures than successes, due to, among other reasons, the lack of survival and/or proper growth of the inoculated microbial strains, owing to their lack of ecological competence in the recipient soil (Lacalle et al., 2020).

Due to their immutable nature, metal(oid)s cannot be degraded and, then, the field of metal bioremediation was at first centered on the possibility of using microbes to detoxify them by valence transformation [e.g., reduction of $\mathrm{Cr}(\mathrm{VI})$ to $\mathrm{Cr}(\mathrm{III})$; reduction of selenite or selenate to elemental selenium] (Garbisu et al., 1996; Garbisu et al., 1998), precipitation (Lovley, 1993), or biotransformation resulting in enhanced adsorption on mineral surfaces (Banerjee et al., 2018). But, apart from some metal(oid)s that can be volatilized as a result of biological activity, the rest, inevitably, still remain in the soil. Besides, the reduced metal mobility and bioavailability achieved by the abovementioned microbial transformation-precipitation processes can be reverted with time, due to unforeseen changes in environmental conditions.

\section{PHYTOREMEDIATION}

Partly due to the impossibility to degrade metal(oid)s, the field of phytoremediation emerged proposing the use of metal tolerant plants to extract these metallic contaminants from soil (phytoextraction) or, alternatively, to reduce their mobility, bioavailability and, hence, toxicity (phytostabilization). Many plant species have shown their remarkable capacity to accumulate metals in their shoots, such as, for instance, Noccaea caerulescens (formerly known as Thlaspi caerulescens) (Epelde et al., 2008) and Sedum plumbizincicola for $\mathrm{Zn}$ and Cd (Deng et al., 2016), and Alyssum bertolonii for Ni (Robinson et al., 1997). Regrettably, phytoextraction has serious drawbacks, most importantly, the great deal of time required to effectively phytoextract the metals from the soil (Zhao et al., 2003), but also the incapability of most hyper(accumulators) to accumulate more than one metal (Burges et al., 2018). Similarly, since phytostabilization, by definition, does not reduce total metal concentrations in soil, there is always the possibility that the immobilized metals are later mobilized due to changes in soil conditions (Alkorta et al., 2010; Lacalle et al., 2020). Importantly, most environmental legislations are based on total metal concentrations, not on bioavailable metal concentrations, leading to the impracticability of this phytotechnology from a legal point of view. This fact invalidates all those phytoremediation options aimed at removing the bioavailable contaminant fraction ("bioavailable contaminant stripping"), a target which considerably reduces the length of time required for soil remediation while addressing contaminant linkages (Moreira et al., 2021). In some countries, regulators are starting to consider bioavailability in risk assessment frameworks, but its 
implementation remains complicated because scientific developments on bioavailability are not easily translated into ready-to-use approaches for regulators (Ortega-Calvo et al., 2015).

In an attempt to overcome the limitations of phytoremediation (a phytotechnology which can certainly be also used for the remediation of soils contaminated with organic compounds and, interestingly, mixed contaminated soils), phytomanagement emerged as an alternative strategy focused on the use of plants and associated microorganisms to decrease contaminant linkages and maximize the provision of ecosystem services, while providing economic revenues by producing non-food crops for biomass-processing technologies (Cundy et al., 2016). The phytomanagement vision ("search for other benefits during plant-based remediation") has signified a critical advance for the practical application of plant-based remediation technologies. However, the plant-based recovery of contaminated sites must not lose focus on its initial target, i.e. the reduction of contaminant concentrations and, hence, risk for human and environmental health. After all, remediation is usually performed once the corresponding authority has decided that an unacceptable risk exists and, for such risk to occur, three elements must be present: a source of contamination, a receptor, and a pathway along which the contaminant can reach the receptor (the so-called "contaminant linkage" or "sourcepathway-receptor link"). Remediation strategies aim to break, or at least reduce as much as possible, the contaminant linkage by eliminating the contaminant, blocking the pathway of exposure, or protecting the receptor. This fully accepted paradigm works much better when humans are the only receptors under consideration. The possibility of blocking the pathways or protecting the receptors is much more remote when dealing with the myriad of biological species that can be exposed to the potentially adverse effects of soil contaminants. Therefore, the most desirable outcome of any remediation process is to eliminate the contaminant(s) provided this goal is achieved in an environmentally-friendly way.

\section{SYMBIOSIS APPROACHES}

As described above, the bioremediation field was initially focused on the microbial degradation of contaminants, while phytoremediation deals with the use of plants to remediate contaminated soils. However, in the last years, symbiosis approaches have gained momentum in the biological remediation field. Thus, microbial-assisted phytoremediation addresses the inoculation of plant growth-promoting microorganisms (rhizosphere bacteria, endophytes, mycorrhiza) to improve the effectiveness of phytoremediation initiatives (Burges et al., 2016). Likewise, plant-assisted bioremediation (also termed rhizodegradation or phytostimulation) exploits the potential of plant establishment and growth to accelerate the microbial degradation of organic contaminants in the rhizosphere (Lacalle et al., 2018). These symbiosis approaches have emerged from the realization that plants are covered in microorganisms (i.e., the rhizosphere, phyllosphere and endosphere microbiomes) which are essential for plant growth, health and performance (in return, plants provide microorganisms with food and a habitat subjected to less competition and fewer stresses) (Chialva et al., 2022). In other words, the biological remediation field is currently interested in the many possibilities that the "holobiont approach" offers (the term holobiont refers to a host and its associated communities of microorganisms, which can co-evolve in response to evolutionary pressures and environmental conditions) (Simon et al., 2019).

In microbial-assisted phytoremediation, microorganisms can alleviate metal induced phytotoxicity, via their own metal resistance system, and improve plant growth under metal exposure, either directly, by enhancing the efficiency of nutrient acquisition by plants and producing phytohormones ("fertilizer effect"), or indirectly by reducing the negative impact of phytopathogens ("pesticide effect") (Sharma, 2021). Interestingly, within the agricultural arena, some authors (Baez-Rogelio et al., 2017) emphasized the possibility of inoculating microorganisms able to simultaneously carry out both plant growth promotion and the bioremediation of contaminated soils derived from intensive farming. For the selection of plant growth-promoting bacteria, which will later be inoculated as single strain formulations or consortia of different strains (in order to emulate more natural rhizomicrobiome systems) (Rosier et al., 2021), several plant growth-promoting traits are normally tested: 1aminocyclopropane-1-carboxylate deaminase activity, nitrogen fixation, phosphorus solubilization, potassium solubilization, indolacetic acid production, siderophore production, production of hydrolytic enzymes (e.g., $\alpha$-amylase, cellulase, chitinase, pectinase, protease), antibiotic production, hydrogen cyanide production, ammonia production, fungal antagonistic activity, etc. (Glick, 2012; Dinesh et al., 2015; Burges et al., 2017; Hyder et al., 2020). It must be emphasized that all these lab-tested traits only represent potentiality but not reality, since the inoculated microbial strains must also show ecological competence and functional performance in the specific soilplant system under consideration (actually, in many cases, they do not survive or grow properly, or do not produce the required phenotype, once they have been inoculated) (Nelson, 2004; Backer et al., 2018). But the painful truth is that, after decades of bioaugmentation research, we still do not know how to properly determine a priori the ecological competence of the microbial strains intended for inoculation. Many efforts have been directed towards identifying "ecological competence traits" (e.g., size, motility, growth rate, capacity to use carbon sources, biofilm formation, salinity tolerance, $\mathrm{pH}$ range, etc.) but, undoubtedly, much more knowledge is still needed to correctly and reliably identify the specific traits than can increase (better, ensure) the fitness of the inoculated strains in a given soil-plant system. Most importantly, for an effective microbial-assisted phytoremediation, we must think beyond the binary interactions between the inoculated microorganisms and the host plants, and thoroughly assess the relationships among the microbial inoculants themselves, as well as between them and the native soil and plant microbiomes. In this line of thought, some authors (Calvo et al., 2014; Vorholt et al., 2017; Paredes et al., 


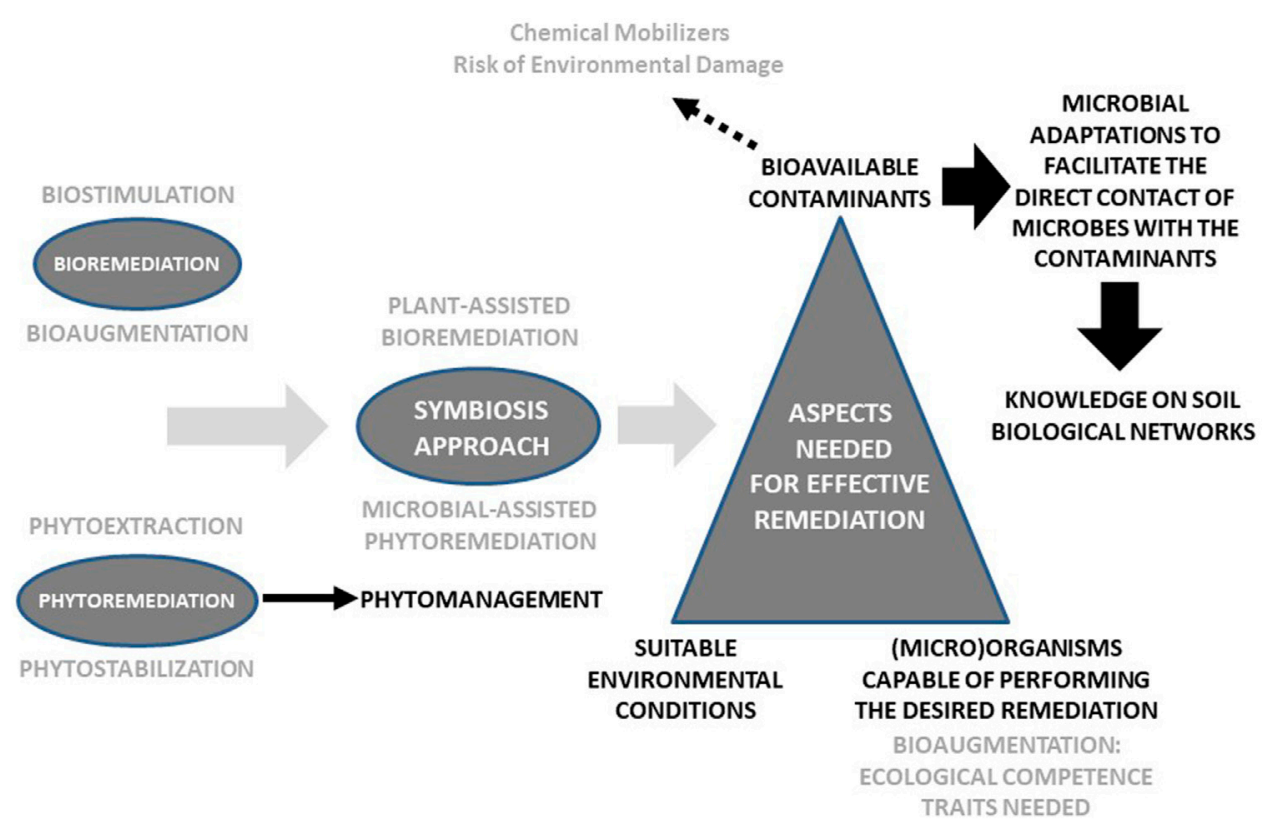

FIGURE 1 | Visual representation of the paper.

2018; Ray et al., 2020) pointed out that we must design "intelligent" consortia that rely on cross-talk, cross-feeding and/or substrate channeling among the different microorganisms, as well as between them and the plants. Thus, in the inoculum formulations, we can combine the microbial strains with relevant signaling molecules, such as nodulation factors (Jaiswal et al., 2021) or molecules involved in quorum sensing or biofilm formation, to facilitate biological communications (Mabood et al., 2014; De Souza et al., 2015; Rosier et al., 2018). Indeed, plant growth-promoting bacteria can respond to plant exudates through the modulation of the expression of different genes, such as those encoding exopolysaccharide biosynthesis and biofilm formation (Meneses et al., 2011; Beauregard et al., 2013). Cell-cell communication via quorum sensing also regulates bacterial root colonization (Danhorn and Fuqua, 2007). Similarly, stress-induced bacterial genes have been linked to plantbacterial interactions. In this respect, Alquéres et al. (2013) found that the bacterial enzymes superoxide dismutase and glutathione reductase were essential for the endophytic colonization of rice roots by Gluconacetobacter diazotrophicus PAL5. Regarding these molecular interactions, it must be taken into consideration that the nutrient rich rhizosphere is a highly competitive niche, where bacteria must develop a variety of traits (e.g., motility, attachment, growth rate, stress resistance, secondary metabolite production, quorum sensing) for ecological competence purposes (De Souza et al., 2015).

Finally, plant-assisted bioremediation, based on the potential stimulatory effect of plant growth on the activity of rhizosphere microorganisms (e.g., via the exudation of easily degradable carbon sources and oxygen transport), presents some of the same limitations associated to all plant-based remediation technologies: root depth, area covered by the roots (contaminants can be in the bulk soil), time required for plant growth, etc. (Moreira et al., 2021). In order to overcome these limitations, the use of transgenic plants in phytoremediation has often been proposed (Doty, 2008; Ozyigit et al., 2021).

\section{RESEARCH NEEDS}

For biological remediation to successfully take place in a given soil, three key factors must be present: suitable environmental conditions (e.g., soil nutrients, $\mathrm{pH}$, temperature, moisture); (micro)organisms capable of remediating the contaminants at a reasonable rate; and the contaminants must be bioavailable (Figure 1). A lot of research has been done on biostimulation, to provide the right environment for remediation, and bioaugmentation, specifically in the search for contaminantdegrading and plant growth-promoting strains (nevertheless, much research is needed regarding the identification of ecological competence traits). Paradoxically, one of the most discussed notions within the remediation field, i.e. contaminant bioavailability, is still one of the main constraints for the success of biological remediation (Kim et al., 2015; OrtegaCalvo et al., 2015; Ren et al., 2018). Much research has been done on the application of chemical substances, such as surfactants and biosurfactants (Mishra et al., 2021), to enhance contaminant bioavailability and, hence, the biodegradation of POPs. Similarly, chelating agents have been used to increase metal bioavailability (Alkorta et al., 2004; Santos et al., 2006). But bioavailability is a two-edged sword: bioavailability is indeed required for biodegradation and remediation but, at the same time, the bioavailable fraction of the contaminants is the one that 
causes the most environmental impact. That is why the application of chemical mobilizing agents is often not recommended since, in many cases, it results in water contamination and a more negative impact on the soil biota (Alkorta et al., 2004), failing to fulfil the paradigm that the goal of any remediation process must be not only to decrease contaminant concentrations but to restore soil health.

It is therefore crucial to design innovative strategies aimed at enhancing the contact between the contaminants and the remediating organisms, but without adding potentially damaging mobilizing agents. In this respect, microbial chemotaxis has been observed to improve contaminant bioavailability (Krell et al., 2013) and, consequently, the application of chemotactic microorganisms can enhance contaminant biodegradation (Pandey et al., 2009). Nonetheless, bacterial motility in porous media, such as the soil matrix, can be limited due to adhesion to particles and high cell deposition rates. To minimize this problem, the role of chemical effectors on bacterial tactic responses must be carefully examined. In this respect, some authors (JiménezSánchez et al., 2018) have reported the positive impact of dissolved organic matter, root exudates, and humic acids in triggering bacterial transport to distant contaminant sources. In addition, soil microbial networks (e.g., fungal mycelia) can facilitate contaminant mobilization and distribution (Furuno et al., 2012; Fester et al., 2014; Ray et al., 2018). Also, myceliapromoted bacterial dispersal (through the so-called fungal highways) can enhance contaminant degradation (Otto et al., 2016), acting as biological effectors. Interestingly, bacteria can alter their cell wall composition and surface change in response to compounds with low bioavailability (Ren et al., 2018). Moreover, microorganisms can secrete electron shuttles which can transfer electrons between the cell surface and POPs, thus facilitating redox biotransformation (Yang et al., 2012), as well as produce extracellular enzymes that can degrade remotely located contaminants. Finally, the formation of biofilms on contaminant-sources can facilitate the direct contact of bacteria with the contaminants. However, although the term soil biofilm is often used, the reality is that biofilms are seldom observed in soils (Baveye, 2021). Actually, what one finds in the soil matrix are small, isolated groups of cells sheathed in partially degraded organic matter, extracellular polymeric substances, and fine textured mineral particles (Baveye, 2021).

A lot of research is needed to better understand all these morphological, behavioral and physiological microbial adaptations (Ren et al., 2018) to then enhance contaminant

\section{REFERENCES}

Ali, H., Khan, E., and Sajad, M. A. (2013). Phytoremediation of heavy metalsConcepts and applications. Chemosphere 91, 869-881. doi:10.1016/ j.chemosphere.2013.01.075

Alkorta, I., Becerril, J. M., and Garbisu, C. (2010). Phytostabilization of metal contaminated soils. Rev. Environ. Health 25, 135-146. doi:10.1515/ reveh.2010.25.2.135

Alkorta, I., Hernández-Allica, J., Becerril, J. M., Amezaga, I., Albizu, I., Onaindia, M., et al. (2004). Chelate-enhanced phytoremediation of soils polluted with bioavailability without harming the environment. Furthermore, as rightly pointed out by Ren et al. (2018), since soil amendments (e.g., compost, biochar, nanomaterials) are more and more used in remediation initiatives, we need to better understand how these amendments can affect contaminant bioavailability directly or indirectly through their effects on the abovementioned microbial adaptations.

Lastly, it is important to remember that soil biodiversity, especially microbial diversity, is the biological infrastructure than supports the soil biological networks that, in turn, are responsible for soil functioning (including contaminant degradation) and resilience against disturbances (including contamination). The understanding of soil biological networks (complex adaptive systems that constitute one of the most complex and fascinating works of biological architecture) is one of the biggest challenges of ecological research and, in particular, soil science. The combination of advanced genomic approaches (Chandran et al., 2020) and ecological network analysis offers unmatched opportunities to map complex plant-microbe interactions and, specifically, to address how such interactions are altered by environmental changes and disturbances (Bennett et al., 2019; Sharma, 2021). As pointed out by Borchert et al. (2021), remediation research efforts should shift from searching for desired traits of monocultures to those of highly integrated multispecies microbial communities.

\section{DATA AVAILABILITY STATEMENT}

The original contributions presented in the study are included in the article/Supplementary Material, further inquiries can be directed to the corresponding author.

\section{AUTHOR CONTRIBUTIONS}

IA and CG took part in the conceptualization, writing and editing of the manuscript. IA and CG revised and approved the final version of the manuscript.

\section{FUNDING}

This work was supported by the European Union through the Interreg SUDOE Program (Project Phy2SUDOE SOE4/P5/ E1021).

heavy metals. Re/Views Environ. Sci. Bio/Technology 3, 55-70. doi:10.1023/b: resb.0000040057.45006.34

Alquéres, S., Meneses, C., Rouws, L., Rothballer, M., Baldani, I., Schmid, M., et al. (2013). The bacterial superoxide dismutase and glutathione reductase are crucial for endophytic colonization of rice roots by Gluconacetobacter Diazotrophicus PAL5. Mpmi 26, 937-945. doi:10.1094/mpmi-12-12-0286-r

Backer, R., Rokem, J. S., Ilangumaran, G., Lamont, J., Praslickova, D., Ricci, E., et al (2018). Plant growth-promoting rhizobacteria: Context, mechanisms of action, and roadmap to commercialization of biostimulants for sustainable agriculture. Front. Plant Sci. 9, 1473. doi:10.3389/fpls.2018.01473 
Baez-Rogelio, A., Morales-García, Y. E., Quintero-Hernández, V., and MuñozRojas, J. (2017). Next generation of microbial inoculants for agriculture and bioremediation. Microb. Biotechnol. 10, 19-21. doi:10.1111/1751-7915.12448

Banerjee, A., Jhariya, M. K., Yadav, D. K., and Raj, A. (2018). "Micro-Remediation of Metals: A New Frontier in Bioremediation," in Handbook of Environmental Materials Management. Editor C. M. Hussain (Cham): Springer, 1-36. doi:10.1007/978-3-319-58538-310.1007/978-3-319-58538-3_10-1

Barrutia, O., Garbisu, C., Epelde, L., Sampedro, M. C., Goicolea, M. A., and Becerril, J. M. (2011). Plant tolerance to diesel minimizes its impact on soil microbial characteristics during rhizoremediation of diesel-contaminated soils. Sci. Total Environ. 409, 4087-4093. doi:10.1016/j.scitotenv.2011.06.025

Baveye, P. C. (2021). Soil "biofilms": "Bioclusters" would be a much better descriptor. Spanish J. Soil Sci. 11 (1). doi:10.3232/SJSS.2021.V11.N1.01

Beauregard, P. B., Chai, Y., Vlamakis, H., Losick, R., and Kolter, R. (2013). Bacillus subtilis biofilm induction by plant polysaccharides. Proc. Natl. Acad. Sci. 110, E1621-E1630. doi:10.1073/pnas.1218984110

Bennett, A. E., Evans, D. M., and Powell, J. R. (2019). Potentials and pitfalls in the analysis of bipartite networks to understand plant-microbe interactions in changing environments. Funct. Ecol. 33, 107-117. doi:10.1111/13652435.13223

Borchert, E., Hammerschmidt, K., Hentschel, U., and Deines, P. (2021). Enhancing microbial pollutant degradation by integrating eco-evolutionary principles with environmental biotechnology. Trends Microbiol. Available online 31 March 2021. doi:10.1016/j.tim.2021.03.002

Burges, A., Alkorta, I., Epelde, L., and Garbisu, C. (2018). From phytoremediation of soil contaminants to phytomanagement of ecosystem services in metal contaminated sites. Int. J. Phytoremediation 20, 384-397. doi:10.1080/ 15226514.2017 .1365340

Burges, A., Epelde, L., Benito, G., Artetxe, U., Becerril, J. M., and Garbisu, C. (2016). Enhancement of ecosystem services during endophyte-assisted aided phytostabilization of metal contaminated mine soil. Sci. Total Environ. 562, 480-492. doi:10.1016/j.scitotenv.2016.04.080

Burges, A., Epelde, L., Blanco, F., Becerril, J. M., and Garbisu, C. (2017). Ecosystem services and plant physiological status during endophyte-assisted phytoremediation of metal contaminated soil. Sci. Total Environ. 584-585, 329-338. doi:10.1016/j.scitotenv.2016.12.146

Calvo, P., Nelson, L., and Kloepper, J. W. (2014). Agricultural uses of plant biostimulants. Plant Soil 383, 3-41. doi:10.1007/s11104-014-2131-8

Chandran, H., Meena, M., and Sharma, K. (2020). Microbial biodiversity and bioremediation assessment through omics approaches. Front. Environ. Chem. 1, 570326. doi:10.3389/fenvc.2020.570326

Chialva, M., Lanfranco, L., and Bonfante, P. (2022). The plant microbiota: composition, functions, and engineering. Curr. Opin. Biotechnol. 73, 1-8. doi:10.1016/j.copbio.2021.07.003

Cundy, A. B., Bardos, R. P., Puschenreiter, M., Mench, M., Bert, V., Friesl-Hanl, W., et al. (2016). Brownfields to green fields: Realising wider benefits from practical contaminant phytomanagement strategies. J. Environ. Manage. 184, 67-77. doi:10.1016/j.jenvman.2016.03.028

Danhorn, T., and Fuqua, C. (2007). Biofilm formation by plant-associated bacteria. Annu. Rev. Microbiol. 61, 401-422. doi:10.1146/ annurev.micro.61.080706.093316

Deng, L., Li, Z., Wang, J., Liu, H., Li, N., Wu, L., et al. (2016). Long-term field phytoextraction of zinc/cadmium contaminated soil bySedum plumbizincicolaunder different agronomic strategies. Int. J. Phytoremediation 18, 134-140. doi:10.1080/15226514.2015.1058328

Dinesh, R., Anandaraj, M., Kumar, A., Bini, Y. K., Subila, K. P., and Aravind, R. (2015). Isolation, characterization, and evaluation of multi-trait plant growth promoting rhizobacteria for their growth promoting and disease suppressing effects on ginger. Microbiol. Res. 173, 34-43. doi:10.1016/j.micres.2015.01.014

Doty, S. L. (2008). Enhancing phytoremediation through the use of transgenics and endophytes. New Phytol. 179, 318-333. doi:10.1111/j.1469-8137.2008.02446.x

Epelde, L., Becerril, J. M., Hernández-Allica, J., Barrutia, O., and Garbisu, C. (2008). Functional diversity as indicator of the recovery of soil health derived from Thlaspi caerulescens growth and metal phytoextraction. Appl. Soil Ecol. 39, 299-310. doi:10.1016/j.apsoil.2008.01.005

Epelde, L., Burges, A., Mijangos, I., and Garbisu, C. (2014). Microbial properties and attributes of ecological relevance for soil quality monitoring during a chemical stabilization field study. Appl. Soil Ecol. 75, 1-12. doi:10.1016/ j.apsoil.2013.10.003

FAO (2020). Towards a definition of soil health. Intergovernmental Technical Panel on Soils. Food and Agriculture Organization of the United Nations. Soil Lett. \# 1. 20 September 2020.

Fester, T., Giebler, J., Wick, L. Y., Schlosser, D., and Kästner, M. (2014). Plantmicrobe interactions as drivers of ecosystem functions relevant for the biodegradation of organic contaminants. Curr. Opin. Biotechnol. 27, 168-175. doi:10.1016/j.copbio.2014.01.017

Furuno, S., Foss, S., Wild, E., Jones, K. C., Semple, K. T., Harms, H., et al. (2012). Mycelia promote active transport and spatial dispersion of polycyclic aromatic hydrocarbons. Environ. Sci. Technol. 46, 5463-5470. doi:10.1021/es300810b

Garbisu, C., Alkorta, I., Llama, M. J., and Serra, J. L. (1998). Aerobic chromate reduction by Bacillus subtilis. Biodegradation 9, 133-141. doi:10.1023/a: 1008358816529

Garbisu, C., Ishii, T., Leighton, T., and Buchanan, B. B. (1996). Bacterial reduction of selenite to elemental selenium. Chem. Geology. 132, 199-204. doi:10.1016/ s0009-2541(96)00056-3

G. Lacalle, R., M. Becerril, J., and Garbisu, C. (2020). Biological methods of polluted soil remediation for an effective economically-optimal recovery of soil health and ecosystem services. J. Environ. Sci. Public Health 04, 112-133. doi:10.26502/ jesph.96120089

Glick, B. R. (2012). Plant growth-promoting bacteria: Mechanisms and applications. Scientifica 2012, 1-15. doi:10.6064/2012/963401

Gómez-Sagasti, M. T., Epelde, L., Alkorta, I., and Garbisu, C. (2016). Reflections on soil contamination research from a biologist's point of view. Appl. Soil Ecol. 105, 207-210. doi:10.1016/j.apsoil.2016.04.004

Hassan, A., Pariatamby, A., Ossai, I. C., and Hamid, F. S. (2020). Bioaugmentation assisted mycoremediation of heavy metal and/metalloid landfill contaminated soil using consortia of filamentous fungi. Biochem. Eng. J. 157, 107550. doi:10.1016/j.bej.2020.107550

Herrera Paredes, S., Gao, T., Law, T. F., Finkel, O. M., Mucyn, T., Teixeira, P. J. P. L., et al. (2018). Design of synthetic bacterial communities for predictable plant phenotypes. Plos Biol. 16, e2003962. doi:10.1371/ journal.pbio.2003962

Hussain, I., Puschenreiter, M., Gerhard, S., Schöftner, P., Yousaf, S., Wang, A., et al. (2018). Rhizoremediation of petroleum hydrocarbon-contaminated soils: Improvement opportunities and field applications. Environ. Exp. Bot. 147, 202-219. doi:10.1016/j.envexpbot.2017.12.016

Hyder, S., Gondal, A. S., Rizvi, Z. F., Ahmad, R., Alam, M. M., Hannan, A., et al. (2020). Characterization of native plant growth promoting rhizobacteria and their anti-oomycete potential against Phytophthora capsici affecting chilli pepper (Capsicum annum L.). Sci. Rep. 10, 13859. doi:10.1038/s41598-02069410-3

Jaiswal, S. K., Mohammed, M., Ibny, F. Y. I., and Dakora, F. D. (2021). Rhizobia as a source of plant growth-promoting molecules: Potential applications and possible operational mechanisms. Front. Sustain. Food Syst. 4, 619676. doi:10.3389/fsufs.2020.619676

Jiménez-Sánchez, C., Wick, L. Y., and Ortega-Calvo, J.-J. (2018). Impact of chemoeffectors on bacterial motility, transport, and contaminant degradation in sand-filled percolation columns. Environ. Sci. Technol. 52, 10673-10679. doi:10.1021/acs.est.8b02370

Kim, R.-Y., Yoon, J.-K., Kim, T.-S., Yang, J. E., Owens, G., and Kim, K.-R. (2015). Bioavailability of heavy metals in soils: definitions and practical implementation-a critical review. Environ. Geochem. Health 37, 1041-1061. doi:10.1007/s10653-015-9695-y

Krell, T., Lacal, J., Reyes-Darias, J. A., Jiménez-Sánchez, C., Sungthong, R., and Ortega-Calvo, J. J. (2013). Bioavailability of pollutants and chemotaxis. Curr. Opin. Biotechnol. 24, 451-456. doi:10.1016/j.copbio.2012.08.011

Lacalle, R. G., Gómez-Sagasti, M. T., Artetxe, U., Garbisu, C., and Becerril, J. M. (2018). Brassica napus has a key role in the recovery of the health of soils contaminated with metals and diesel by rhizoremediation. Sci. Total Environ. 618, 347-356. doi:10.1016/j.scitotenv.2017.10.334

Lovley, D. R. (1993). Dissimilatory metal reduction. Annu. Rev. Microbiol. 47, 263-290. doi:10.1146/annurev.mi.47.100193.001403

Mabood, F., Zhou, X., and Smith, D. L. (2014). Microbial signaling and plant growth promotion. Can. J. Plant Sci. 94, 1051-1063. doi:10.4141/CJPS2013-148 
Megharaj, M., Ramakrishnan, B., Venkateswarlu, K., Sethunathan, N., and Naidu, R. (2011). Bioremediation approaches for organic pollutants: a critical perspective. Environ. Int. 37, 1362-1375. doi:10.1016/j.envint.2011.06.003

Meneses, C. H. S. G., Rouws, L. F. M., Simões-Araújo, J. L., Vidal, M. S., and Baldani, J. I. (2011). Exopolysaccharide production is required for biofilm formation and plant colonization by the nitrogen-fixing endophyte Gluconacetobacter Diazotrophicus. Mpmi 24, 1448-1458. doi:10.1094/mpmi05-11-0127

Mishra, S., Lin, Z., Pang, S., Zhang, Y., Bhatt, P., and Chen, S. (2021). Biosurfactant is a powerful tool for the bioremediation of heavy metals from contaminated soils. J. Hazard. Mater. 418, 126253. doi:10.1016/j.jhazmat.2021.126253

Moreira, H., Pereira, S. I. A., Mench, M., Garbisu, C., Kidd, P., and Castro, P. M. L. (2021). Phytomanagement of metal(loid)-contaminated soils: Options, efficiency and value. Front. Environ. Sci. 9, 661423. doi:10.3389/fenvs.2021.661423

Nelson, L. M. (2004). Plant growth promoting rhizobacteria (PGPR): Prospects for new inoculants. Crop Manag. 3, 1-7. doi:10.1094/CM-2004-0301-05-RV

Ortega-Calvo, J.-J., Harmsen, J., Parsons, J. R., Semple, K. T., Aitken, M. D., Ajao, C., et al. (2015). From bioavailability science to regulation of organic chemicals. Environ. Sci. Technol. 49, 10255-10264. doi:10.1021/acs.est.5b02412

Otto, S., Banitz, T., Thullner, M., Harms, H., and Wick, L. Y. (2016). Effects of facilitated bacterial dispersal on the degradation and emission of a desorbing contaminant. Environ. Sci. Technol. 50, 6320-6326. doi:10.1021/acs.est.6b00567

Ozyigit, I. I., Can, H., Dogan, I., Can, H., and Dogan, I. (2021). Phytoremediation using genetically engineered plants to remove metals: A review. Environ. Chem. Lett. 19, 669-698. doi:10.1007/s10311-020-01095-6

Pandey, J., Chauhan, A., and Jain, R. K. (2009). Integrative approaches for assessing the ecological sustainability ofin situbioremediation. Fems Microbiol. Rev. 33, 324-375. doi:10.1111/j.1574-6976.2008.00133.x

Poi, G., Aburto-Medina, A., Mok, P. C., Ball, A. S., and Shahsavari, E. (2017). Large scale bioaugmentation of soil contaminated with petroleum hydrocarbons using a mixed microbial consortium. Ecol. Eng. 102, 64-71. doi:10.1016/ j.ecoleng.2017.01.048

Ray, P., Chi, M.-H., Guo, Y., Chen, C., Adam, C., Kuo, A., et al. (2018). Genome sequence of the plant growth-promoting fungus Serendipita vermifera subsp. bescii: The first native strain from North America. Phytobiomes 2, 2471-2906. doi:10.1094/pbiomes-04-17-0017-a

Ray, P., Lakshmanan, V., Labbé, J. L., and Craven, K. D. (2020). Microbe to microbiome: A paradigm shift in the application of microorganisms for sustainable agriculture. Front. Microbiol. 11, 622926. doi:10.3389/fmicb.2020.622926

Ren, X., Zeng, G., Tang, L., Wang, J., Wan, J., Liu, Y., et al. (2018). Sorption, transport and biodegradation - An insight into bioavailability of persistent organic pollutants in soil. Sci. Total Environ. 610-611, 1154-1163. doi:10.1016/ j.scitotenv.2017.08.089

Robinson, B. H., Chiarucci, A., Brooks, R. R., Petit, D., Kirkman, J. H., Gregg, P. E. H., et al. (1997). The nickel hyperaccumulator plant Alyssum bertolonii as a potential agent for phytoremediation and phytomining of nickel. J. Geochemical Exploration 59, 75-86. doi:10.1016/s0375-6742(97)00010-1

Rosier, A., Beauregard, P. B., and Bais, H. P. (2021). Quorum quenching activity of the PGPR Bacillus subtilis UD1022 alters nodulation efficiency of Sinorhizobium meliloti on Medicago truncatula. Front. Microbiol. 11, 596299. doi:10.3389/fmicb.2020.596299

Rosier, A., Medeiros, F. H. V., and Bais, H. P. (2018). Defining plant growth promoting rhizobacteria molecular and biochemical networks in beneficial plant-microbe interactions. Plant Soil 428, 35-55. doi:10.1007/s11104-0183679-5

Santos, F. S., Hernández-Allica, J., Becerril, J. M., Amaral-Sobrinho, N., Mazur, N., and Garbisu, C. (2006). Chelate-induced phytoextraction of metal polluted soils with Brachiaria decumbens. Chemosphere 65, 43-50. doi:10.1016/ j.chemosphere.2006.03.012

Sharma, P. (2021). Efficiency of bacteria and bacterial assisted phytoremediation of heavy metals: An update. Bioresour. Tech. 328, 124835. doi:10.1016/ j.biortech.2021.124835

Simon, J-C., Marchesi, J. R., Mougel, C., and Selosse, M-A. (2019). Host-microbiota interactions: from holobiont theory to analysis. Microbiome 7, 5. doi:10.1186/ s40168-019-0619-4

Souza, R. d., Ambrosini, A., and Passaglia, L. M. P. (2015). Plant growth-promoting bacteria as inoculants in agricultural soils. Genet. Mol. Biol. 38, 401-419. doi:10.1590/S1415-475738420150053

Vorholt, J. A., Vogel, C., Carlström, C. I., and Müller, D. B. (2017). Establishing causality: Opportunities of synthetic communities for plant microbiome research. Cell Host \& Microbe 22, 142-155. doi:10.1016/j.chom.2017.07.004

Wartell, B., Boufadel, M., and Rodriguez-Freire, L. (2021). An effort to understand and improve the anaerobic biodegradation of petroleum hydrocarbons: A literature review. Int. Biodeterioration Biodegradation 157, 105156. doi:10.1016/j.ibiod.2020.105156

Wu, M., Wu, J., Zhang, X., and Ye, X. (2019). Effect of bioaugmentation and biostimulation on hydrocarbon degradation and microbial community composition in petroleum-contaminated loessal soil. Chemosphere 237, 124456. doi:10.1016/j.chemosphere.2019.124456

Yang, Y., Xu, M., Guo, J., and Sun, G. (2012). Bacterial extracellular electron transfer in bioelectrochemical systems. Process Biochem. 47, 1707-1714. doi:10.1016/j.procbio.2012.07.032

Zaborowska, M., Wyszkowska, J., and Kucharski, J. (2019). Biochemical activity of soil contaminated with BPS, bioaugmented with a mould fungi consortium and a bacteria consortium. Environ. Sci. Pollut. Res. 26, 37054-37069. doi:10.1007/ s11356-019-06875-4

Zhao, F. J., Lombi, E., and McGrath, S. P. (2003). Assessing the potential for zinc and cadmium phytoremediation with the hyperaccumulator Thlaspi caerulescens. Plant Soil 249, 37-43. doi:10.1023/a:1022530217289

Conflict of Interest: The authors declare that the research was conducted in the absence of any commercial or financial relationships that could be construed as a potential conflict of interest.

Publisher's Note: All claims expressed in this article are solely those of the authors and do not necessarily represent those of their affiliated organizations, or those of the publisher, the editors and the reviewers. Any product that may be evaluated in this article, or claim that may be made by its manufacturer, is not guaranteed or endorsed by the publisher.

Copyright (c) 2021 Alkorta and Garbisu. This is an open-access article distributed under the terms of the Creative Commons Attribution License (CC BY). The use, distribution or reproduction in other forums is permitted, provided the original author(s) and the copyright owner(s) are credited and that the original publication in this journal is cited, in accordance with accepted academic practice. No use, distribution or reproduction is permitted which does not comply with these terms. 